Revista de BIOLOGía TROPICAL

\title{
Distribución espacio-temporal de la temperatura, salinidad y oxígeno disuelto alrededor del Domo Térmico de Costa Rica
}

\section{Omar G. Lizano}

Centro de Investigación en Ciencias del Mar y Limnología (CIMAR), Centro de Investigaciones Geofísicas (CIGEFI), Departamento de Física Atmosférica, Oceánica y Planetaria (DFAOP), Escuela de Física, Universidad de Costa Rica, 11501-2060 San José, Costa Rica, Fax: (506) 2207-3280, omar.lizano@ucr.ac.cr

\section{Recibido 06-III-2014. Corregido 20-VI-2015. Aceptado 09-IX-2015.}

\begin{abstract}
Spatio-temporal distribution of temperature, salinity and dissolved oxygen around the Costa Rica Thermal Dome. The Costa Rica Thermal Dome (CRTD) is an oceanographic phenomenon in the Eastern Tropical Pacific (ETP). This is a region of very high biological productivity, resulting in high concentrations of phytoplankton, sea birds, and large pelagics, such as tunas, dolphins and whales. Few publications have looks at the station variability of the water column of the CRTD. Here, horizontal and vertical distribution of some oceanic parameters was analyzed to show the dynamics of ETP, its influence on the CRTD, climatic variations and relationships that justify their distributions. Climatological monthly mean data of Ocean Data View (ODV) from 1900 to 2009 were used to compile profiles of the water column's temperature, salinity and dissolved oxygen, and their spatial distributions around the Costa Rica Thermal Dome (CRTD). Monthly variations of these parameters depend on the intensity and extent of ocean-meteorological phenomena in the Eastern Tropical Pacific (ETP), which are related to the north-south migration of Intertropical Convergence Zone (ITCZ). The monthly climatic variation of these variables is analyzed down to $200 \mathrm{~m}$ depth. Increased climate variability is found in the water column at stations north and east of the CRTD. The two stations north of the CRTD, closer to the coast, are the ones most affected by the wind in front of the Gulf of Papagayo and where the greatest monthly upwelling variation occurs in this region. The distribution and concentration of dissolved oxygen depends on the ocean-atmospheric dynamics. Oxygen is consumed by respiration and organic matter oxidation around CRTD. Moreover, this is one of the regions of the tropical oceans where an Oxygen Minimum Zone (OMZ) exist, which is related also to poor water circulation or lack ocean ventilation. Sources of dissolved oxygen are linked with sub-surface currents coming from the west and from the south of the geographic equator. Rev. Biol. Trop. 64 (Suppl. 1): S135-S152. Epub 2016 February 01.
\end{abstract}

Key words: Ocean Data View, climatology, Eastern Tropical Pacific, Costa Rica Thermal Dome, dissolved oxygen.

La dinámica del Pacífico Tropical Este (PTE) se ha estudiado desde los trabajos de Wyrtki (1964; 1966; 1967). Adicionalmente se realizó una revisión de literatura del PTE en una serie de artículos en un Número Especial (Volumen 69) de Progress in Oceanography (Kessler, 2006; Fiedler, \& Talley, 2006; Amador, Alfaro, Lizano, \& Magaña, 2006; Willett, Leben, \& Lavín, 2006), basado en una recopilación de datos de las últimas décadas. Es claro a través de todos estos trabajos, que la dinámica de esta zona está ligada a los fuertes vientos que atraviesan a lo largo de los pasos topográficos de Tehuantepec al sur de México, el Golfo de Papagayo en el Pacífico norte de Costa Rica y el Golfo de Panamá. La variación estacional del viento y la oscilación meridional de la Zona de Convergencia Intertropical (ZCIT) (e.g. Quirós, 2015; Hidalgo, Durán-Quesada, Amador, \& Alfaro, 2015), modifican la dinámica del PTE (Kessler, 2006).

Varios trabajos se han escrito sobre el Domo Térmico de Costa Rica (DTCR) por su singular productividad (Wyrtki, 1964; Umatani, 
\& Yamagata, 1991; Fiedler, 1992; Fiedler, 1994), entre otros. Wyrtki (1964) indica que el Domo Térmico de Costa Rica fue encontrado en 1948 después de examinar los datos de batitermógrafos (BT) tomados por los barcos que hacían la ruta entre California y Panamá. Aunque Wyrtki (1964) menciona que algunas expediciones se hicieron entre 1952 y 1958 , no fue sino hasta 1959 en que su estudio determinó el tamaño, posición y variabilidad de este domo; y esto fue en respuesta a la necesidad de evaluar las fuentes del atún para la InterAmerican Tropical Tuna Commission. Según Fieldler (2002), el Domo de Costa Rica fue observado por primera vez por Klaus Wyrtki en 1948 y descrito por Cromwell (1958), y su posición promedio es alrededor de los $9^{\circ} \mathrm{N}$ y $90^{\circ} \mathrm{W}$ (Fiedler, 2002). Consiste en un levantamiento hacia la superficie de la termoclina, lo cual genera un domo de isotermas a través de la columna de agua (Brenes, Lavín, \& Mascarenhas, 2008). Se encuentra en el Pacífico Tropical Este (PTE) a lo largo de un dorsal o cresta térmica que separa la Contracorriente Ecuatorial Norte (que fluye al este), de la Corriente Ecuatorial Norte (que fluye al oeste) (Wyrtki, 1964; Fiedler, 2002). Tiene un diámetro de 300-500 km, centrado a unos $300 \mathrm{~km}$ al oeste del Golfo de Papagayo, entre Costa Rica y Nicaragua. El tope de la termoclina está a unos $15 \mathrm{~m}$ de profundidad. Esta se hace gradualmente menos profunda desde el oeste hacia el este, y cae más rápidamente conforme se aproxima a la costa (Fiedlder, 2002). Las razones que se han dado para justificar este afloramiento o surgencia de aguas sub-superficiales (de entre 75-200m de profundidad, Writky, 1964), que da origen al Domo Térmico, han sido variadas. Wyrtki (1964) postuló que esto era producto de la divergencia del flujo (uno hacia el norte y el otro hacia el sur) de la Contracorriente Ecuatorial Norte cuando se encontraba con la plataforma continental Centroamericana. Sin embargo, este autor despreció el efecto que tiene el viento local sobre la circulación y el afloramiento en esta región (Fiedler, 2002). Hofmann, Busalacchi \& O'Brien (1981) fueron los que propusieron que el afloramiento era generado por "bombeo de Ekman" (surgencia de aguas sub-superficiales), el cual es producto de la rotacional ciclónica (rotación en contra de las manecillas del reloj) que genera la intensificación del viento al frente del Golfo de Papagayo (Shang-Ping, Xu, Kessler, \& Nonaka, 2005; Amador, 2008). Fiedler (2002) estudio la variación estacional del DTCR, y aunque indica que prácticamente hay una permanencia del mismo en la región, la localización y la magnitud varía considerablemente durante el año. Las manifestaciones de afloramiento se dan en la costa cerca del Golfo de Papagayo en febrero-marzo, cuando los vientos son fuertes frente a esta zona (Alfaro et al., 2012; Alfaro, \& Cortes, 2012). En la medida en que los vientos alisios disminuyen, se mueve hacia afuera de la costa durante Abril-Julio. Se intensifica entre Julio y Noviembre, y se debilita entre Diciembre y Enero. Aunque mantiene una circulación superficial ciclónica en balance geostrófico, su ciclo anual está relacionado con la variabilidad de los vientos en esta zona, asociada a la migración de la ZCIT (Fiedler, 2002; Amador et al., 2006). Domos térmicos tropicales existen en el Atlántico del Este (el Domo de Guinea y el Domo de Angola) y en el Pacífico Occidental (Domo de Mindanao) (Kashino, Ishida, \& Hosada, 2011). El Domo de Costa Rica es el único que es forzado por un el chorro de viento costero (Fiedler, 2002; Shang-Ping et al., 2005; Amador, 2008).

Desde los trabajos de Wyrtki (1964), Broenkow (1965), Fielder (2002) y Kessler (2006), se identifica al Domo de Costa Rica como un área de bajas temperaturas superficiales, alta salinidad, alto fosfato y donde el afloramiento produce bajas concentraciones de oxígeno en la superficie. Mientras que por otro lado, las aguas que lo rodean, tienen bajas salinidades, bajo fosfato y altas concentraciones de oxígeno. Uno de los primeros trabajos sobre las propiedades químicas de la columna de agua en el Domo Térmico de Costa Rica, fue hecho por Broenkow (1965), basado en el muestro de un crucero en 1959. Se observó un marcado gradiente de oxígeno, decreciendo de $4.25 \mathrm{ml} / \mathrm{L}$ en la superficie, a $1.04 \mathrm{ml} / \mathrm{L}$ a $50 \mathrm{~m}$. 
La poca concentración de oxígeno en la superficie demuestra la intensidad del afloramiento (Broenkow, 1965). El mínimo de oxígeno, con cantidades indetectables en algunos casos, se encontró desde $300 \mathrm{~m}$ hasta unos $700 \mathrm{~m}$, a partir del cual aumentó con profundidad hasta $1 \mathrm{ml} / \mathrm{L}$ a $1100 \mathrm{~m}$. Este estudio también indica que en el domo se encuentran máximos relativos de oxígeno a aproximadamente $50 \mathrm{~m}$, y que estos máximos pueden estar relacionados a la Corriente Sub-Superficial Ecuatorial (CSSE). Estudios similares sobre estos máximos fueron reportados por Bennett (1963), quien también agrega que estos máximos están relacionados con aguas de alta salinidad y relativamente alto contenido de oxígeno, formadas al sur del ecuador, y que alcanzan esta región por mezcla de la CSSE. El trabajo de Broenkow (1965), también menciona la relación entre los nutrimentos y el oxígeno. El oxígeno disuelto es consumido en la respiración y oxidación de la materia orgánica. Por otro lado, el fósforo, nitrógeno y carbono que se ha combinado químicamente en los organismos, es liberado a la solución como iones de fosfato, nitrato y carbono.

Específicamente sobre la Zona Mínima de Oxígeno (ZMO), varios trabajos se han realizado en esta región. Fernández-Álamo \& FärberLorda (2006) señalan que en el PTE hay aguas con bajo oxígeno dado el alto consumo de este elemento, y a que la advección horizontal es muy débil. Criterio similar expresan Fiedler \& Talley (2006), que indican que la ZMO se encuentra debajo de la capa superficial con alta productividad biológica, donde la producción e intercambio de oxígeno es muy alto. También señalan que las aguas con bajo contenido de oxígeno se extienden a aguas más profundas por donde se decantan partículas orgánicas que son degradadas por descomposición bacterial. Estos autores también muestran que el transporte de aguas oxigenadas desde el Pacífico Occidental a lo largo del ecuador, produce una ZMO con más alta concentración de oxígeno sobre esta región. Agregan que la $\mathrm{ZMO}$ al norte del ecuador se extiende a más de $1000 \mathrm{~m}$ de profundidad. En el Pacífico Sur el espesor de la ZMO varía entre 200 a 600 m, y en el
Pacífico Norte entre 400 a 1100 m. Sobre el Domo Térmico, el límite superior de la isoclina de $1 \mathrm{ml} / \mathrm{L}$ se sitúa a 40-60 m. Karstensen, Stramma \& Visbeck (2008) también agregan que la ZMO es una consecuencia del mínimo reemplazo lateral de las aguas superficiales o falta de "ventilación" de la cuenca a través de una circulación generada por el viento.

Los procesos dinámicos que se dan en el PTE son influenciados por advecciones desde el Pacífico Norte y Pacífico Sur. Muchos de los trabajos realizados en esta zona abarcan una gran extensión del PTE, que deben incluir longitudes de hasta los $180^{\circ}-160^{\circ} \mathrm{W}$ para identificar esta contribuciones (Fiedler, \& Talley, 2006; Pennington et al., 2006). Sin embargo, en la mayoría de ellos es difícil identificar rasgos dinámicos propiamente sobre la región más al este del Pacífico (al este de los $100^{\circ} \mathrm{W}$ ). En esta zona la dinámica oceánica-atmosférica es distinta a regiones más al oeste (Kessler, 2006). Los vientos alisios del Pacífico Sur que cruzan el ecuador, se transforman en los oestes ecuatoriales (Zárate, 1978; Muñoz, Fernández, Gutiérrez, \& Zárate, 2002), con un flujo intenso cuya componente meridional comienza a ser mayor que la zonal a partir de $\operatorname{los} 110^{\circ}-105^{\circ}$ W (Kessler, 2006), y como menciona Fiedler (2002), este fenómeno es la fuente de energía que mantiene el afloramiento durante esta parte del año.

En este artículo se analizan los procesos oceánicos y atmosféricos más importantes en esta zona más al este del PTE, de manera que la resolución espacial permita identificar y correlacionar la variación estacional de algunos parámetros químicos y físicos alrededor del Domo Térmico de Costa Rica. Pocos trabajos se han realizado sobre la variación estacional de la columna de agua en el domo. Esta es una zona con un hábitat biológico altamente productivo, altas concentraciones de plancton, aves marinas, y grandes pelágicos, como atunes, ballenas y delfines. También es un sitio de gran cantidad de mamíferos, como la ballena azul que están en peligro de extinción (Fiedler, 2002; Palacios, Bograd, Foley, \& Schwing, 2006). Además, es parte del corredor 
migratorio de una población de tortugas Baulas que anidan en las playas de Costa Rica. Por eso la importancia de generar información como una herramienta para la protección de estos hábitats marinos.

\section{MATERIALES Y MÉTODOS}

Se usaron datos climatológicos del Ocean Data View (ODV) desde 1900 (Levitus et al., 2013), compilados en la base de datos hasta el 2009, para extraer los parámetros de interés para realizar este artículo. Se seleccionaron perfiles en la columna de agua, en transectos latitudinales y longitudinales alrededor del Domo Térmico de Costa Rica $\left(9.5^{\circ} \mathrm{N}-89.5^{\circ}\right.$ $\mathrm{W})$, para mostrar la variación anual de los datos en esta región (Fig. 1). Se elaboró una base climatológica mensual con los datos del ODV extrayéndolos específicamente para el área comprendida entre $100^{\circ}-70^{\circ} \mathrm{W}$ y $0^{\circ}-18^{\circ}$
$\mathrm{N}$ y hasta la profundidad donde habían datos. Se usaron los datos climatológicos mensuales de precipitación de los reanálisis del National Centers for Environmental Prediction (NCEP) de la National Oceanic and Atmospheric Administration (NOAA) de los Estados Unidos de América (http://apdrc.soest.hawaii.edu/dods/ public_data/Reanalysis_Data/NCEP/NCEP/ clima/surface_gauss/). En todos los casos de las distribuciones espaciales de las variables estudiadas, se ajustó el ámbito de variación (escala del gráfico) al mínimo y máximo valor absoluto de los datos de la misma variable, para identificar mejor los gradientes espaciales de las mismas.

\section{RESULTADOS}

Perfiles típicos hasta aguas profundas: Los perfiles climatológicos mensuales de silicato, nitrato, fosfato, oxígeno disuelto, salinidad

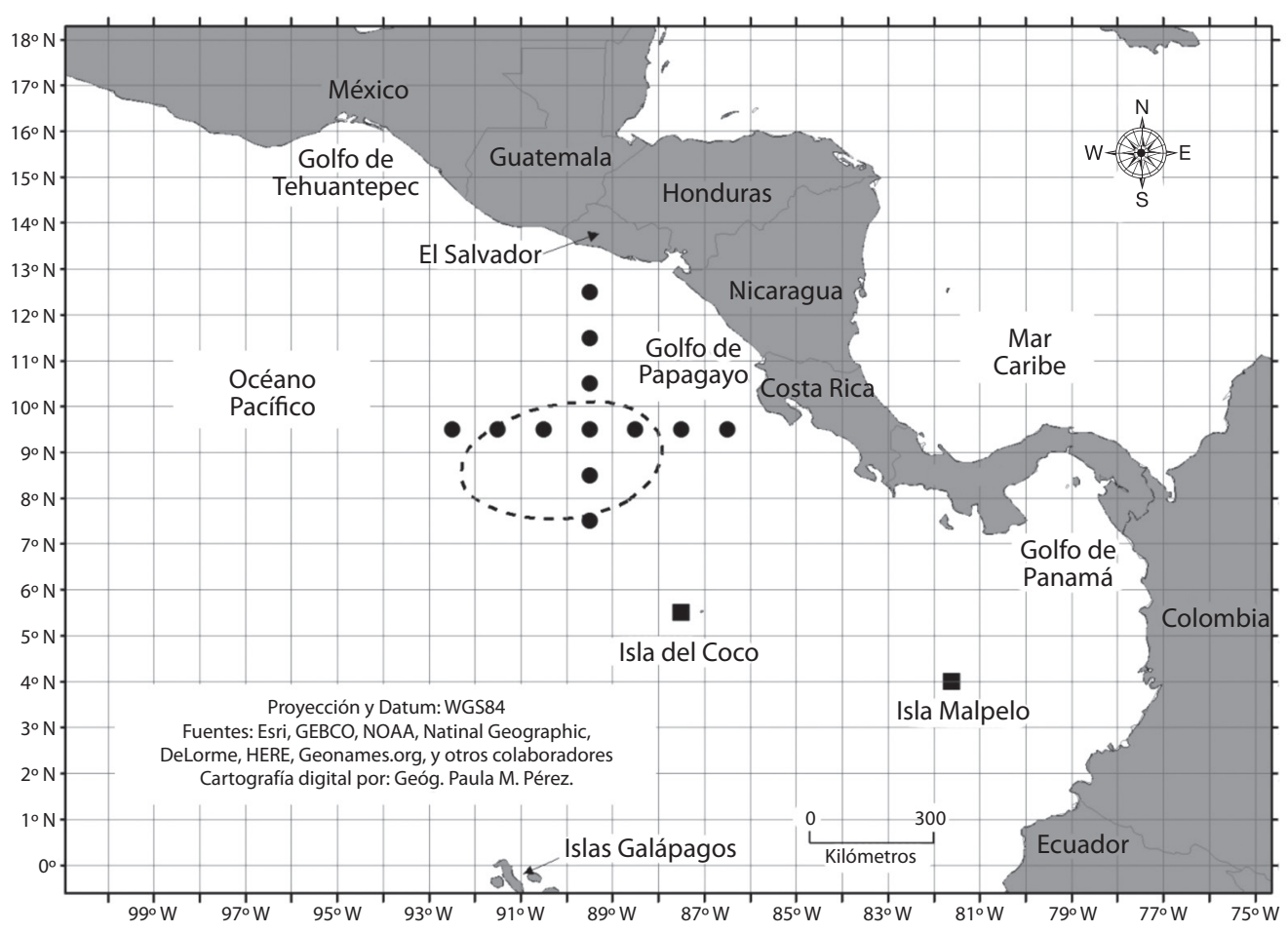

Fig. 1. Área de estudio. Posiciones de las estaciones estudiadas y posición aproximada (línea entrecortada) de Domo Térmico según Fiedler (2002). 
y temperatura de agua para las estaciones en los vértices extremos de los transectos norte-sur y este-oeste de la Fig. 1 correspondiente al mes de enero, se muestran en la Fig. 2. Se encuentra

A

Coordenadas $12.5 \mathrm{~N}-89.5 \mathrm{~W}$

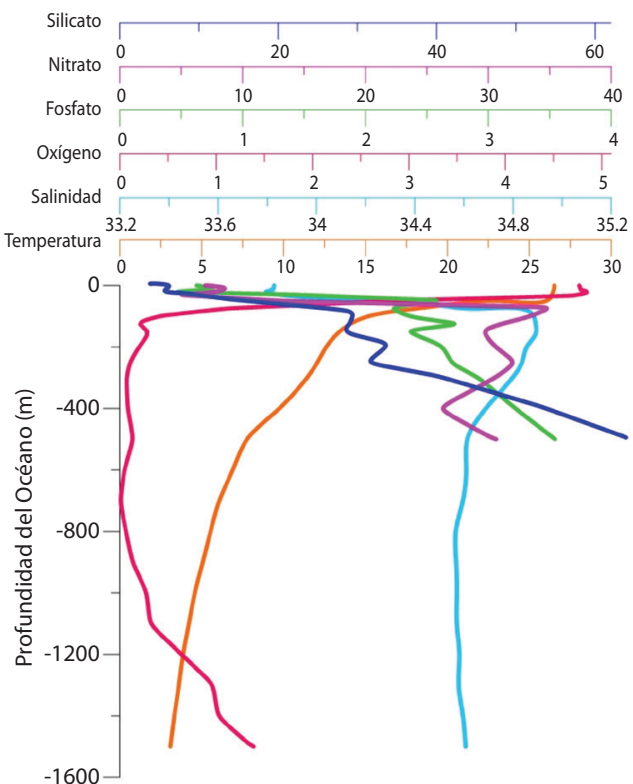

C

Coordenadas $9.5 \mathrm{~N}-92.5 \mathrm{~W}$
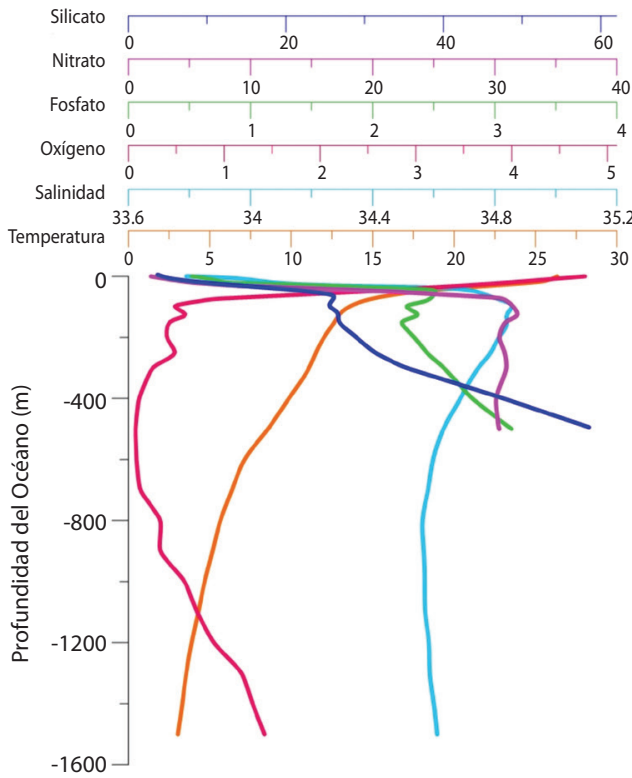

que hay una mayor variación de estos parámetros en la dirección norte-sur que en la dirección este-oeste (Figs. 2A, B). Los perfiles de temperatura, identifican la estructura típica de
B

Coordenadas $9.5 \mathrm{~N}-89.5 \mathrm{~W}$

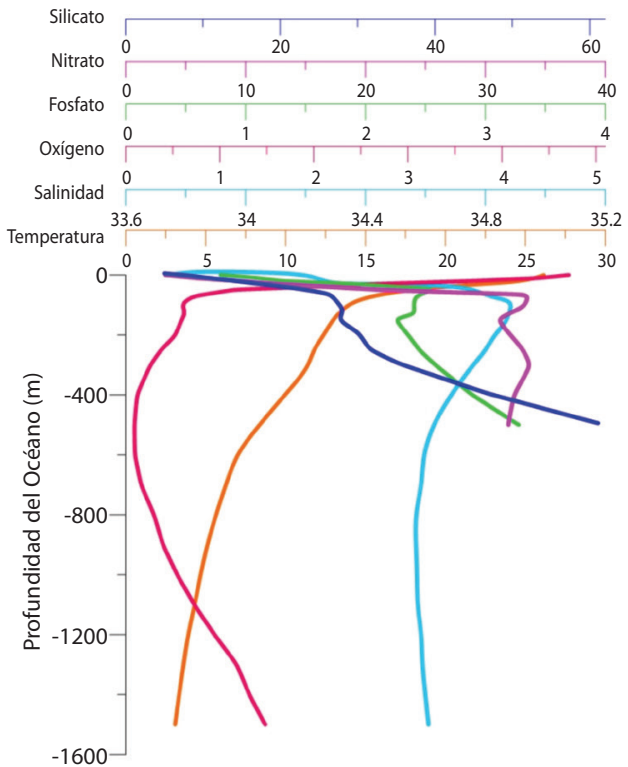

D

Coordenadas $9.5 \mathrm{~N}-86.5 \mathrm{~W}$

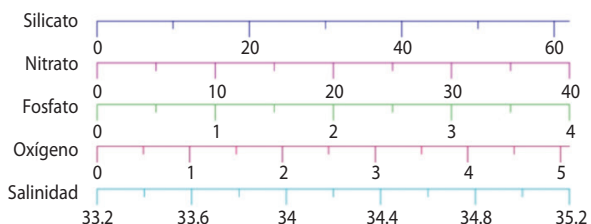

Temperatura $\begin{array}{r}33.2 \\ \hline\end{array}$

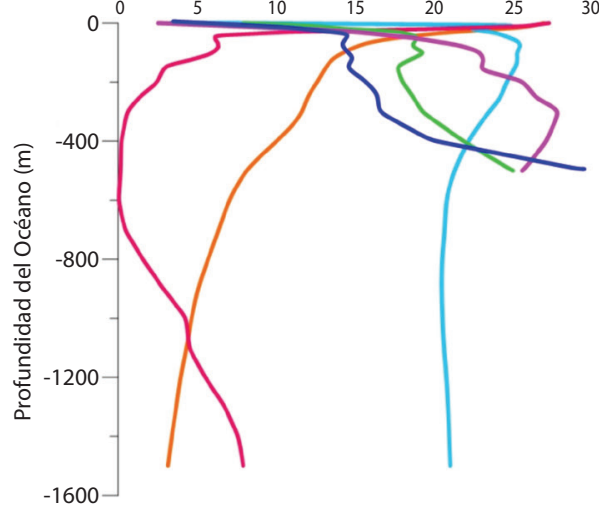

Figs. 2. Perfiles climatológicos para enero de parámetros físico-químicos en la columna de agua. 
esta variable en los océanos tropicales (Knauss, 1978): aguas más cálidas en superficie (25$26^{\circ} \mathrm{C}$ ), una termoclina con un gradiente fuerte en los primeros $100 \mathrm{~m}$, y un decrecimiento más leve conforme aumenta la profundidad. Todos los perfiles indican que, aún a la profundidad máxima de estos datos $(1500 \mathrm{~m})$, la temperatura sigue disminuyendo levemente con profundidad. En todas las estaciones, el perfil de salinidad muestra una haloclina con un gradiente fuerte en los primeros $40 \mathrm{~m}$. Continúa con un máximo relativo entre 50 y $100 \mathrm{~m}$, a partir de la cual se invierte el gradiente de la salinidad, disminuye levemente hasta los 400-500 m, a partir de estas profundidades, se mantiene un valor prácticamente constante con profundidad. La estación más al este, cercana a la costa (Fig. 2D), es la que muestra las variaciones superficiales más fuertes. Los perfiles de oxígeno disuelto muestran una variación espacial distinguible, especialmente en el transecto norte-sur (Figs. 2A, B). Todos los perfiles muestran una oxiclina con un gradiente fuerte de oxígeno en los primeros $100 \mathrm{~m}$, una ZMO (e.g. $<1 \mathrm{ml} / \mathrm{L}$ ), que puede variar de profundidad según la estación, y una inversión de concentración de oxígeno disuelto a mayores profundidades, en algunos casos a partir de los $500 \mathrm{~m}$ (Fig. 2B), y en otros, a profundidades mayores de los $800 \mathrm{~m}$. El perfil de la estación más al norte (Fig. 2A), muestra que la ZMO comienza a menor profundidad que las demás, y que además, ese mínimo va desde los $50 \mathrm{~m}$ hasta profundidades de $600 \mathrm{~m}$. Significativamente más oxigenada es la capa superficial y profunda, de la estación más al sur (alrededor del DTCR) (Fig. 2B). El transecto este-oeste (Figs. 2C, D), no muestra cambio significativo. Sin embargo, son aguas menos oxigenadas que la estación más al sur (Fig. 2B). En todos los casos mostrados en la Fig. 2, los perfiles de silicato, nitrato, fosfato, aumentan con profundidad rápidamente (al menos hasta la profundidad de $400 \mathrm{~m}$, límite de información de estas variables de la base de datos de ODV), en una relación inversa con la disminución del oxígeno.
Distribución de la temperatura superficial del mar. La climatología del ODV de la distribución espacial de la Temperatura Superficial del Océano (TSO) muestra que al principio del año (Fig. 3A) las menores temperaturas se identifican al frente al Golfo de Tehuantepec, el Golfo de Papagayo, el Golfo de Panamá, y al sur, sobre el Ecuador Geográfico. El afloramiento de Papagayo se extiende al suroeste, y es aún sensible en posiciones como los $6^{\circ} \mathrm{S}$ y $95^{\circ} \mathrm{W}$ (Fig. 3A). Aguas más cálidas quedan como siempre atrapadas al frente del Pacífico Sur de Costa Rica (Lizano, 2008), cuyo gradiente de temperatura va más allá de la Isla del Coco, como muestra la Fig. 3A. En el mes de abril, el afloramiento de Tehuantepec desaparece, el del Golfo de Papagayo se mantiene, aunque la extensión espacial de este se reduce. Se hace también, más intenso el gradiente de temperatura al frente al Golfo de Panamá, que se integra al gradiente fuerte de temperatura al sur de $\operatorname{los} 4^{\circ} \mathrm{N}$. En medio de estos afloramientos, se atrapan aguas más calientes, que se extienden desde el sur de Costa Rica, primero hacia el suroeste, a longitudes más allá de la Isla del Coco, y luego al oeste. Abril es el mes de mayor TSM en las aguas de la Isla del Coco. Para julio y octubre (Figs. 3C, D) el afloramiento se despega de la costa y se centra sobre $\operatorname{los} 8-9^{\circ} \mathrm{N}$ y $90^{\circ} \mathrm{W}$, la típica dinámica reportada para el DTCR (Fiedler, 2002).

Variación climática de los perfiles someros de la TSO en el transecto norte-sur del DTCR. Las variaciones climáticas mensuales de la TSO en este transecto (Fig. 4) muestran que el ámbito de variación superficial está entre $26^{\circ} \mathrm{C}$ y algo más que $\operatorname{los} 28^{\circ} \mathrm{C}$. Mayor variación estacional muestran los perfiles al norte de $\operatorname{los} 9.5^{\circ} \mathrm{N}$. En estas estaciones es mayor el cambio de la termoclina para abril y octubre, siendo esta última, la menos profunda, especialmente en la estación más al norte (Fig. 4A). Menor variabilidad estacional en los perfiles al sur de esta posición, siendo el cambio mayor en la capa superficial sobre los $20 \mathrm{~m}$. En general, 

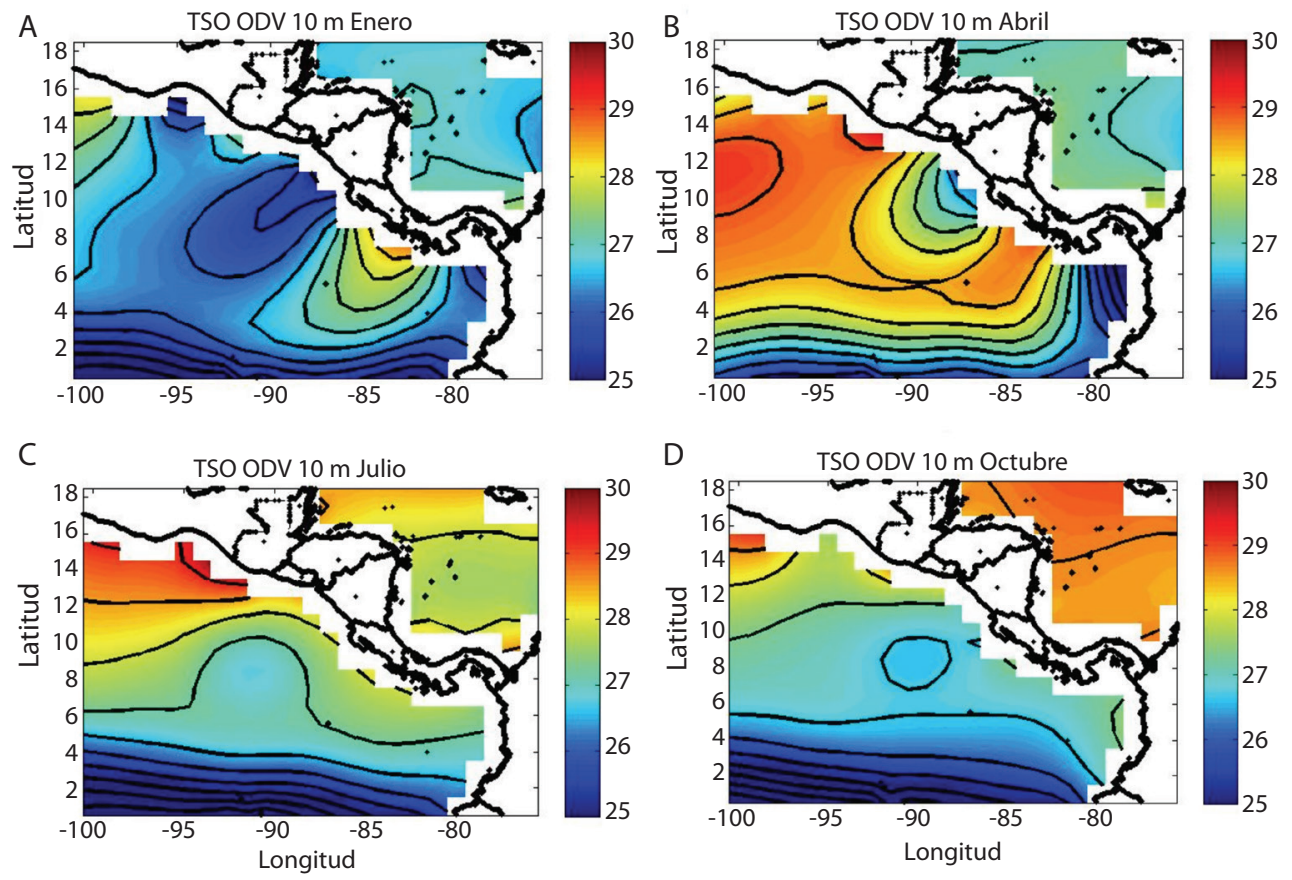

Figs.3. Distribución especial de temperatura $\left({ }^{\circ} \mathrm{C}\right)$ superficial del mar.
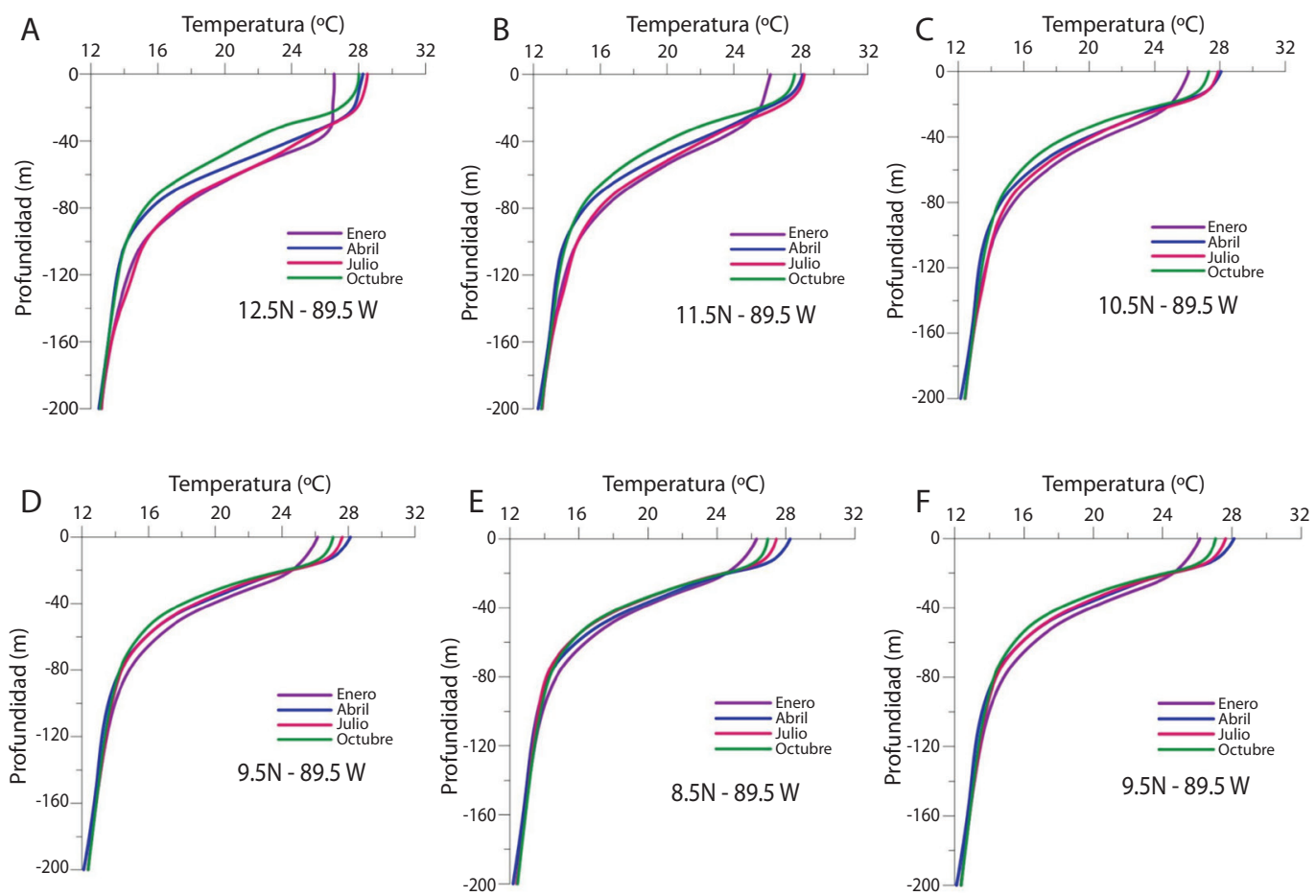

Figs. 4. Perfiles someros de la temperatura $\left({ }^{\circ} \mathrm{C}\right)$ del mar en el transepto norte-sur de Figura 1. 

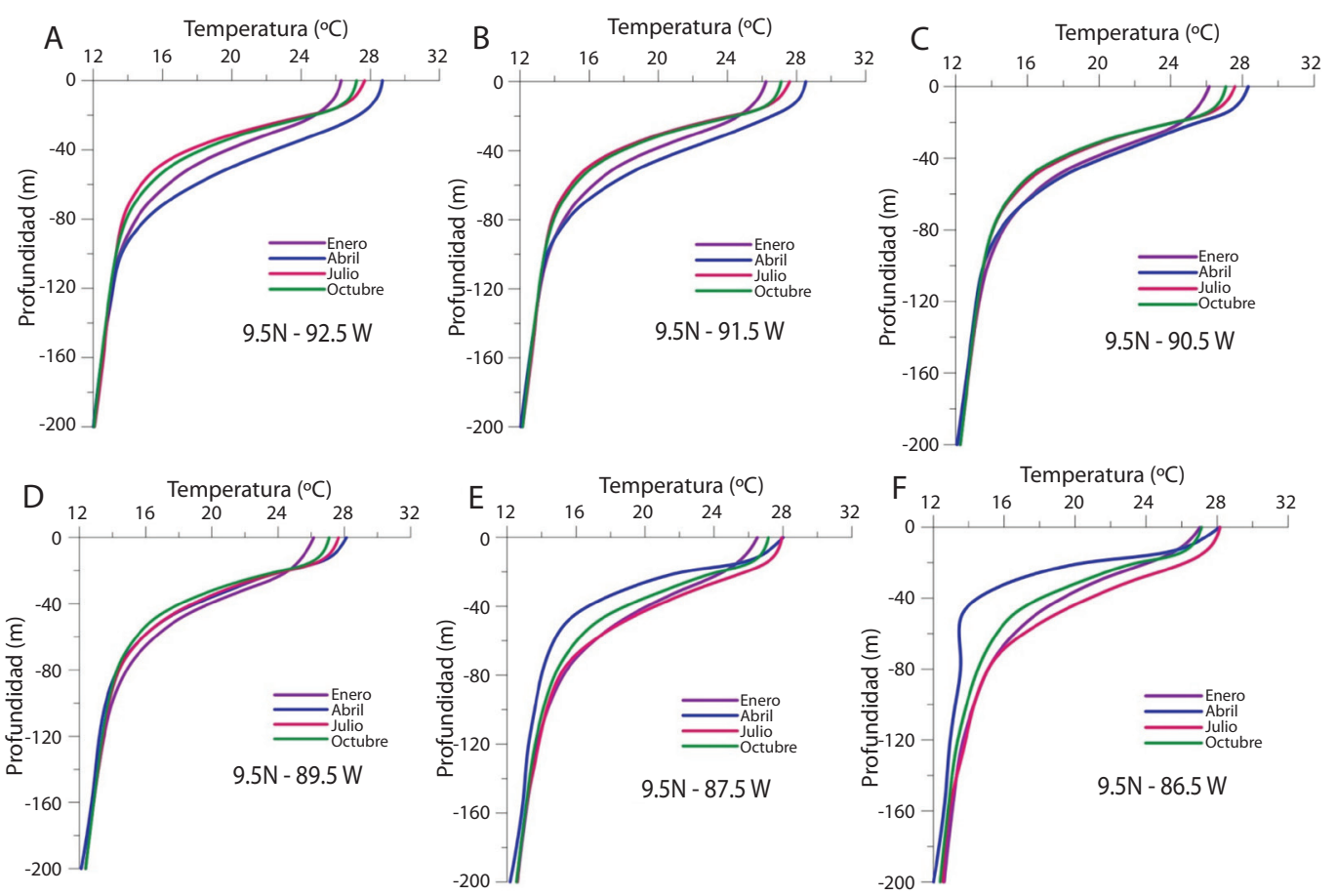

Figs. 5. Perfiles someros de la temperatura $\left({ }^{\circ} \mathrm{C}\right)$ del mar en el transepto oeste-este de Figura 1.

climatológicamente a nivel superficial, el mes más frio es enero $\left(26^{\circ} \mathrm{C}\right)$ y el mes más caliente es abril $\left(28-28.5^{\circ} \mathrm{C}\right)$. En la estación más al norte (Fig. 4A), hay una capa de mezcla más profunda en enero, con un espesor entre $30 \mathrm{y}$ $40 \mathrm{~m}$. Esta estructura de capa de mezcla va desapareciendo en las estaciones más al sur, en las que también, los cambios climatológicos mensuales son menores (Fig. 4). No hay variación estacional en todos los perfiles, a profundidades mayores de $160 \mathrm{~m}$.

Variación climática mensual de los perfiles someros de la TSO en el transecto este-oeste del DTCR. Estos perfiles (Fig. 5) muestran mayor cambio mensual en la termoclina y más variación espacial que el transecto norte-sur. La termoclina muestra mayor variación con profundidad en estas estaciones. En las estaciones al oeste de los $89.5^{\circ} \mathrm{W}$, la termoclina más profunda es en abril, y la menos profunda en octubre (Figs. 5A, B, C). A nivel superficial, el mes más caliente es abril en estas estaciones. La estructura mensual de los perfiles se invierte en la medida que nos desplazamos al este de los $89.5^{\circ} \mathrm{W}$. En este caso, el perfil del mes de abril es el menos profundo, haciéndose más somero en la medida en que se dirige hacia el este, hacia la costa (Fig. 5F). En estas estaciones, el mes de julio es el más caliente a nivel superficial, y con el perfil con la termoclina más profunda.

Distribución superficial de la salinidad. La climatología del ODV de la distribución de la salinidad superficial del océano (SSO) indica que en enero (Fig. 6A) se identifica un máximo relativo al frente del Golfo de Papagayo, y un mínimo superficial de salinidad ( $32 \mathrm{psu}$ ) extenso sobre el lado sureste del Pacífico, frente a Panamá y Colombia. La influencia de este mínimo va más allá de las latitudes ecuatoriales, y al menos hasta longitudes como los $93^{\circ} \mathrm{W}$. Este gradiente de salinidad alcanza a la Isla del Coco. La distribución de salinidad superficial en el mes de abril es muy particular, 

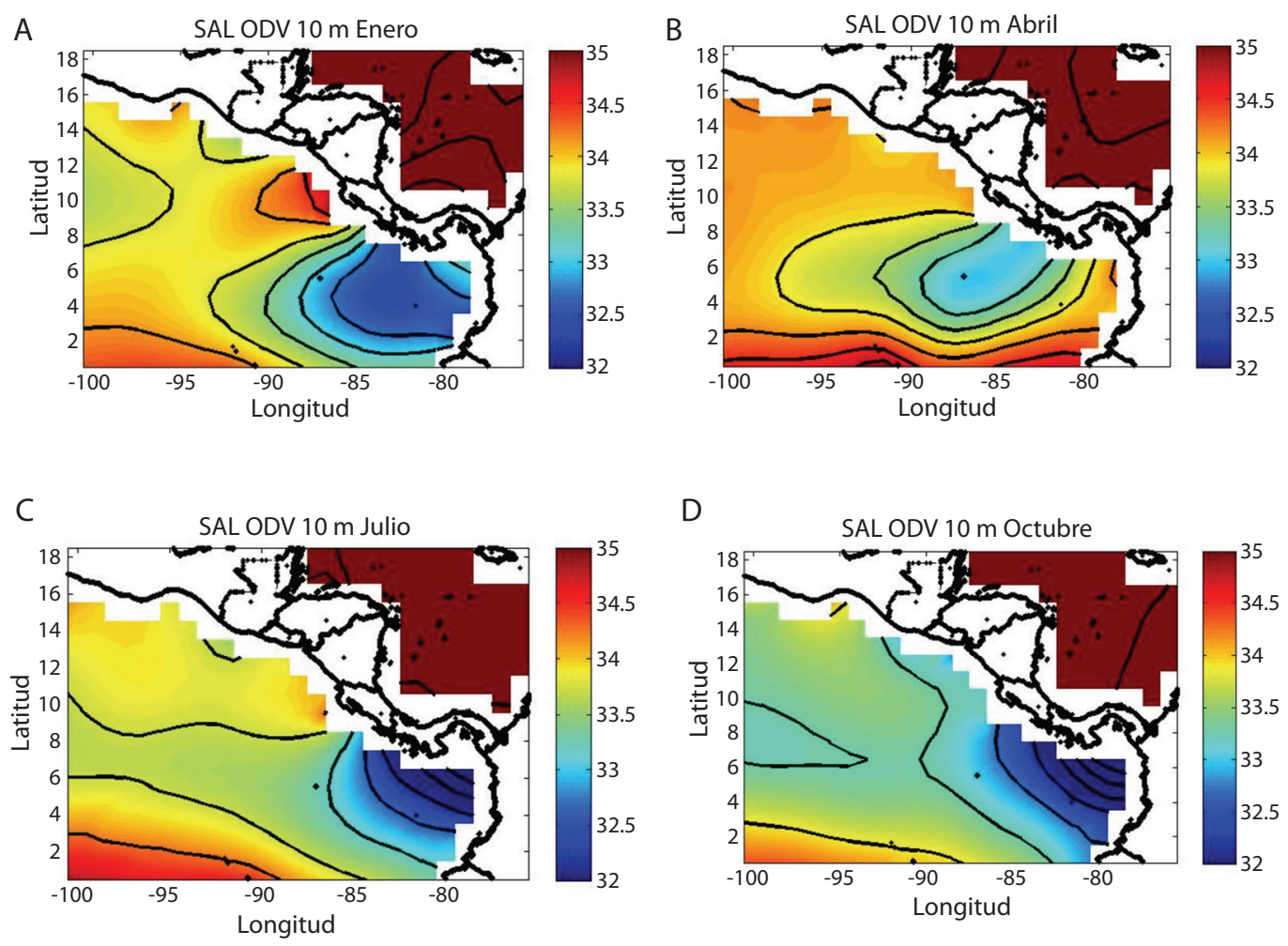

Figs. 6. Distribución espacial de la salinidad (psu) en la superficie del mar.

pues ese mínimo de salinidad (32 psu) se inicia al sur de Costa Rica, con una elongación hacia el suroeste, y rodeado de mayores salinidades superficiales. Aunque no se muestra en este artículo, el mes de marzo es el otro mes que tiene esta característica. En julio y octubre (Figs. 6C, D), el mínimo se recuesta sobre la esquina sureste del PTE. El mes de octubre es el de menor salinidad superficial en toda esta región.

Variación climática de los perfiles someros de la salinidad en el transecto norte-sur del DTCR. La variación climatológica mensual de los perfiles de salinidad en el transecto norte-sur a través del DTCR (Fig. 7) muestra que la variación superficial de la salinidad está entre 33.25 psu y 34.25 psu. Mayor variación estacional tienen los perfiles al norte de los 9.5 $\mathrm{N}$ (Figs. 7A, B, C). El mes de enero y abril registra un menor cambio a lo largo del perfil en todos los casos. En enero se identifican máximos relativos a $10 \mathrm{~m}$ de profundidad, y un mínimo relativo a $20 \mathrm{~m}$ de profundidad, mas marcado en las Figs. 7B y C. El mes de abril es el de mayor salinidad superficial al norte de $\operatorname{los} 9.5^{\circ} \mathrm{N}$ (Figs. 7A, B, C), y enero es el mes el de menor salinidad al sur de esta latitud (Figs. 7D, E, F). El mes de julio tiene las haloclinas con un mayor gradiente vertical en la capa superficial, sobre los $20 \mathrm{~m}$. Para todos los casos, el mes de octubre es el que tiene menor salinidad superficial, y también es el perfil de mayor variación con profundidad, especialmente al norte de los $9.5^{\circ} \mathrm{N}$. Octubre es el mes de mayores variaciones verticales, mostrando haloclinas más profundas, y con gradientes fuertes en la capa superficial, especialmente en las estaciones más al norte (Figs. 7A, B, C). En la estación más al norte (Fig. 7A) se muestra una inversión bien definida de la haloclina a aproximadamente $20 \mathrm{~m}$. Esta inversión se nota 


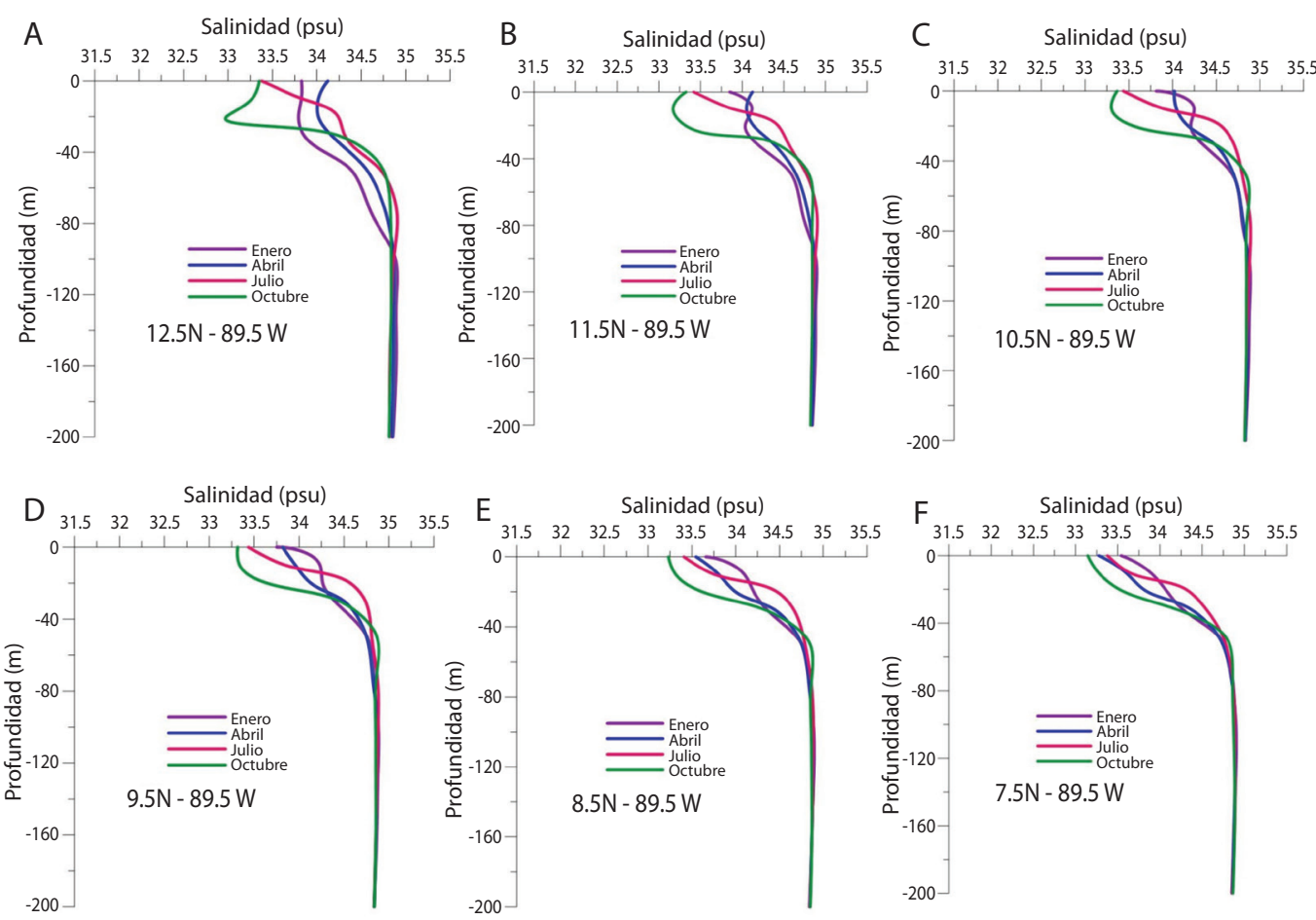

Figs. 7. Perfiles someros de la salinidad (psu) del mar en el transepto norte-sur de Figura 1.

con menor gradiente vertical para los dos perfiles de salinidad en las siguientes dos estaciones más al sur (Figs. 7B, C).

Variación climática de los perfiles someros de la salinidad en el transecto oeste-este del DTCR. En el transecto oeste-este (Fig. 8) la mayor variación climatológica de los perfiles de salinidad, se dan conforme se aproxima a la costa (Figs. 8D, E, F). Enero es un mes de gran variación vertical, mostrando inversiones en el gradiente de salinidad con profundidad, con máximos relativos a $10 \mathrm{~m}$ y mínimos relativos a $20 \mathrm{~m}$, situación que es más evidente en las estaciones más al este (Figs. 8D, E, F). Menor variación vertical en abril, especialmente en las estaciones al oeste de los $89.5^{\circ} \mathrm{W}$ (Figs. 8A, B y C). En este mes también se ve una inversión en el gradiente de salinidad cerca de la costa (Fig. 8F). En julio las termoclinas son menos profundas y de gradientes más fuertes hasta los $20 \mathrm{~m}$. En este mes se ve también, una inversión en el gradiente de salinidad cerca de la costa (Fig. 8F). En octubre se dan las haloclinas más profundas, con gradientes más intensos. Hay una ligera inversión de salinidad alrededor de los $15 \mathrm{~m}$ en las estaciones más al este durante este mes.

Distribución superficial de oxígeno disuelto. Desde las distribuciones superficiales climatológicas de oxígeno disuelto se nota que en enero (Fig. 9A) hay un mínimo relativo ligado ligeramente a la costa de Costa Rica, pero centrado en $90^{\circ} \mathrm{W}-9^{\circ} \mathrm{N}$. Menores valores $(3 \mathrm{ml} / \mathrm{L})$ al frente del Golfo de Panamá (Fig. 9A). En abril el mínimo prácticamente desaparece sobre estas zonas, y más bien se nota un gradiente fuerte de oxígeno al sureste, al frente de Colombia-Ecuador. En julio el mínimo se acerca a las costas de Costa Rica-Nicaragua, y su gradiente apenas alcanza la Isla del Coco. En octubre (Fig. 9D) se tienen los mayores concentraciones superficiales $(5 \mathrm{ml} / \mathrm{L})$ al este de 

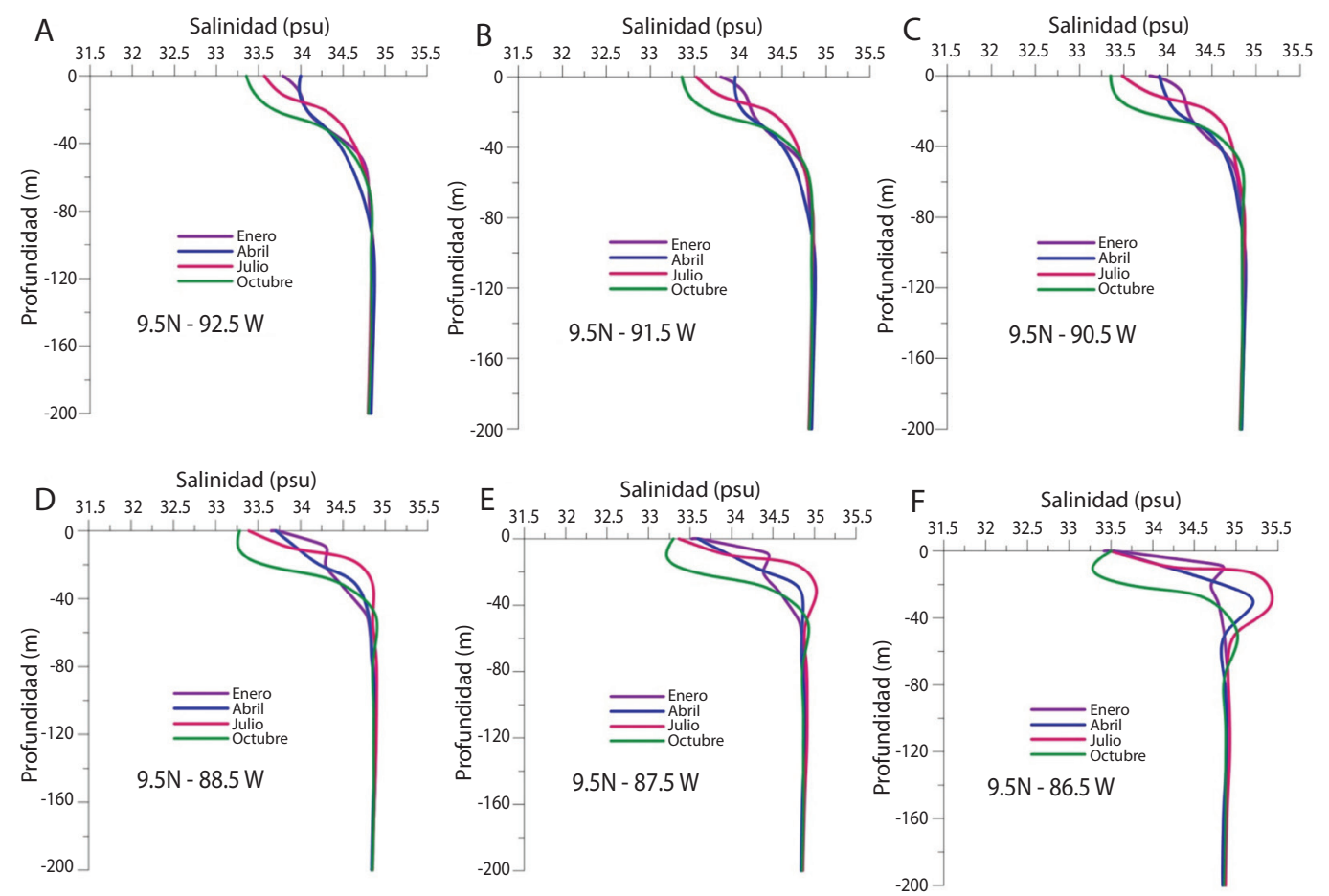

Fig. 8. Perfiles someros de la salinidad (psu) del mar en el transepto oeste-este de Figura 1.

A

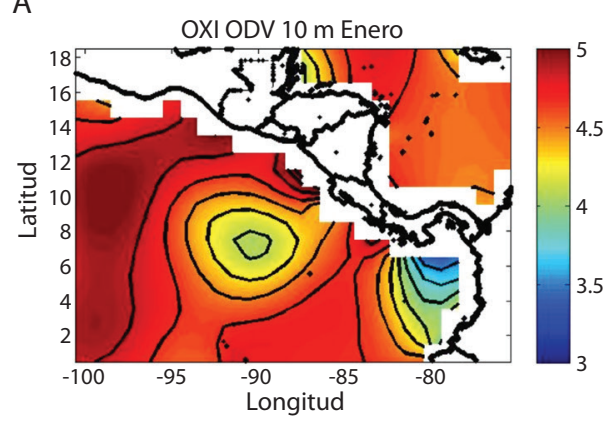

C

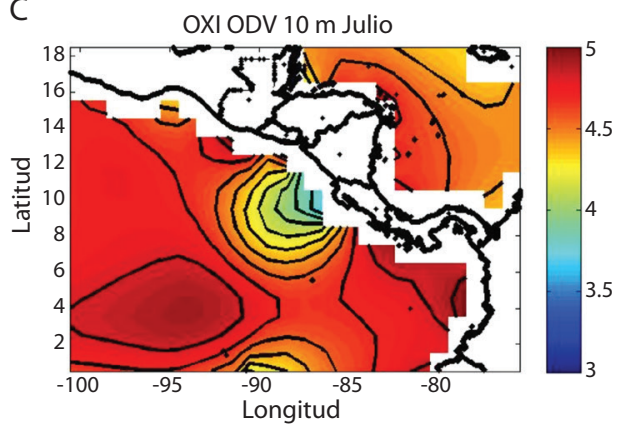

B

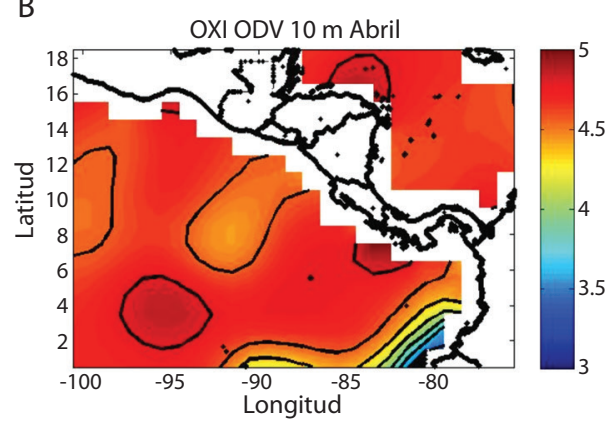

D

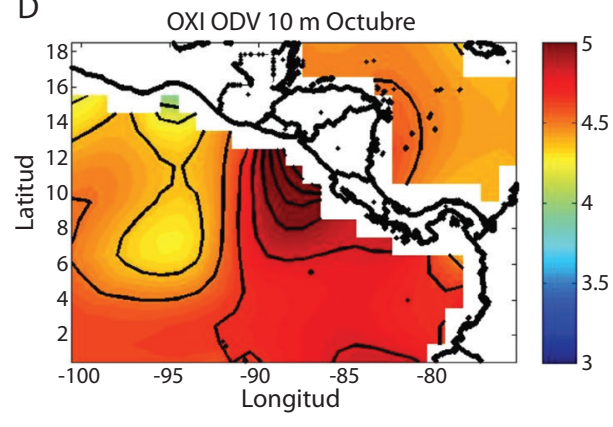

Figs. 9. Distribución espacial del oxígeno disuelto $(\mathrm{ml} / \mathrm{L})$ en la superficie del mar. 
$\operatorname{los} 90^{\circ} \mathrm{W}$, al frente del El Salvador, Nicaragua y Costa Rica. En este mes se nota de nuevo, la influencia de vientos y del afloramiento al frente de Golfo de Tehuantepec, con la disminución superficial de oxígeno disuelto frente a esta región.

Variación climática de los perfiles someros del oxígeno disuelto en el transecto nortesur del DTCR. Los valores superficiales varían en el ámbito de 4 a 5 ml/L (Fig. 10). Hay más variación estacional de los perfiles de oxígeno disuelto en las estaciones al norte de $\operatorname{los} 10.5^{\circ} \mathrm{N}$ (Figs. 10A, B, C). En enero y abril se nota una capa de mezcla bien definida en la estación más al norte. Esta capa de mezcla prácticamente desaparece en las estaciones al sur (Figs. 10D, E, F). La oxiclina es menos profunda en julio para todos los perfiles, especialmente para las estaciones más al norte. La ZMO (valores menores de $1 \mathrm{ml} / \mathrm{L}$ ), puede identificarse a profundidades entre los 40 y $60 \mathrm{~m}$, siendo el mes de julio el mes donde esta ZMO se alcanza a menor profundidad. Estas estaciones también presentan máximos relativos significativos de oxígeno disuelto a profundidades de $20-30 \mathrm{~m}$ ( $>5 \mathrm{ml} / \mathrm{L}$ ), especialmente en octubre. En estas estaciones del norte y en el mes de octubre, también hay un interesante máximo relativo a profundidades de $120-140 \mathrm{~m}$, que desaparece en las estaciones más al sur. En general, la $\mathrm{ZMO}$ se alcanza a mayor profundidad en las estaciones al norte de los $10.5^{\circ} \mathrm{N}$.

Variación climática mensual de los perfiles someros del oxígeno disuelto en el transecto oeste-este del DTCR. En el transecto oeste-este, la oxiclina es menos fuerte en las estaciones al oeste de los $89.5^{\circ} \mathrm{W}$ (Figs. 11A, B, C). En estas estaciones también se identifican máximos relativos $(1 \mathrm{ml} / \mathrm{L})$ a profundidades de 120-140 m. Estos máximos desaparecen en las estaciones más cerca de la costa. Mas sin embargo, en estas últimas se desarrolla un
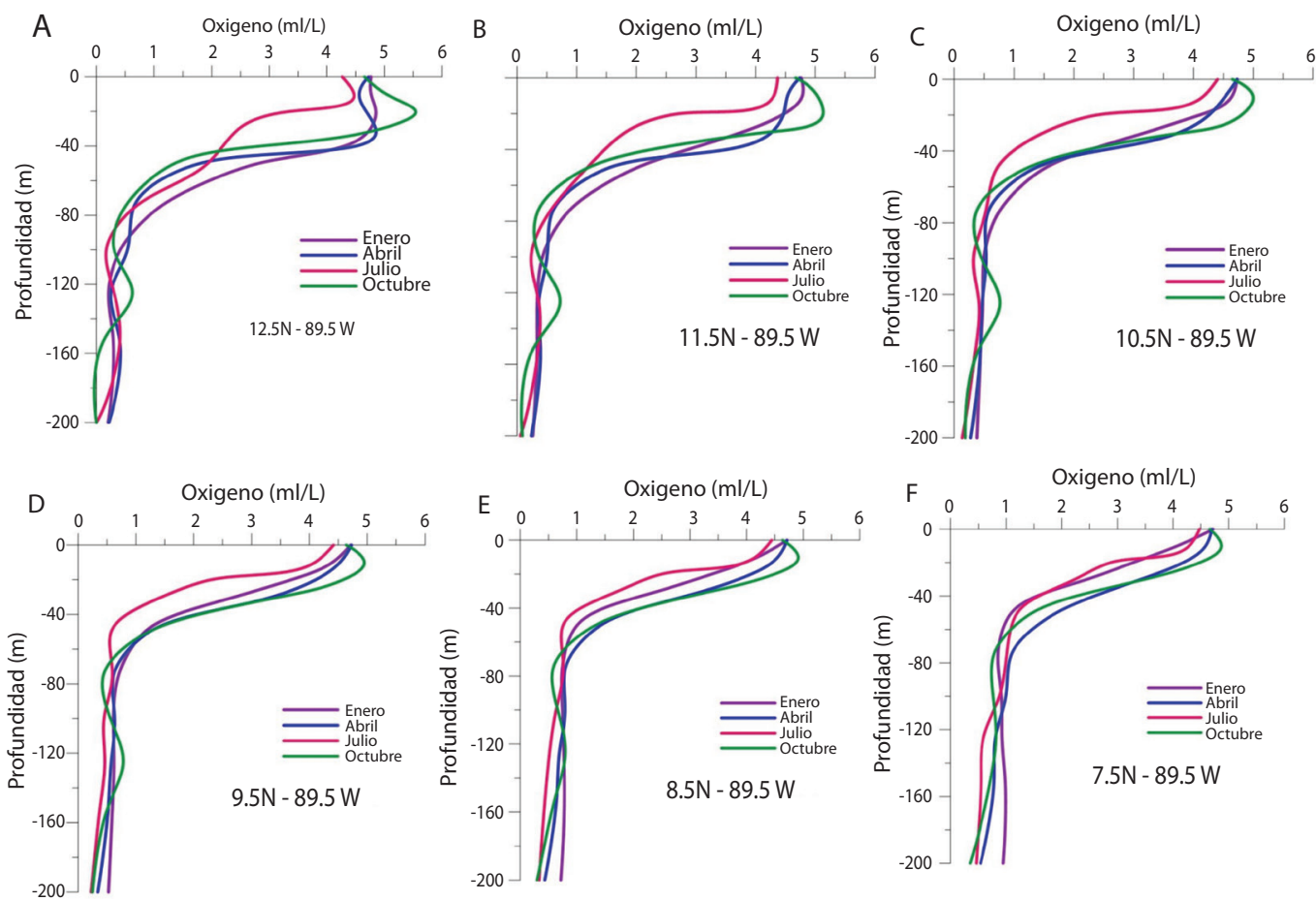

Figs. 10. Perfiles someros del oxígeno disuelto $(\mathrm{ml} / \mathrm{L})$ en el transepto norte-sur de Figura 1. 
máximo relativo de oxígeno disuelto cerca de la superficie en enero y octubre (Figs. 11D, E, F) a profundidades de $10-15 \mathrm{~m}$.

\section{Distribución de oxígeno disuelto a 400m} de profundidad. Dado que la ZMO en esta región se encuentran a alrededor de los $400 \mathrm{~m}$, se interpoló este campo a esa profundidad (Fig. 12). Se nota que la $Z M O$ en enero está al norte de $\operatorname{los} 10^{\circ} \mathrm{N}$, mayores concentraciones al frente del Golfo de Panamá y sobre el ecuador durante este mes. En abril hay un desplazamiento de los mínimos hacia el sur (Fig. 12B), con una distribución prácticamente zonal (contornos de este a oeste). El gradiente de la concentración de oxígeno sobre el ecuador es menor en julio (Fig. 12C). En octubre se tiene la mayor advección de oxígeno disuelto desde las latitudes ecuatoriales (Fig. 12D), advección que se propaga hacia el frente de Colombia y sur de Panamá. En la mayoría de los casos, hay mayores concentraciones de oxígeno disuelto sobre la región sureste del PTE, costa de Colombia y sur de Panamá.

\section{DISCUSIÓN}

Los perfiles exploratorios de algunos parámetros físicos y químicos que se hicieron alrededor del Domo Térmico (Fig. 2), muestran las condiciones típicas que deberían encontrarse en las aguas tropicales: poca variación estacional y gradientes fuertes en la capa superficial (Knauss, 1978). Algunos, como la temperatura y la salinidad, están relacionados con procesos, tanto oceánicos, como atmosféricos en esta zona (Hofmann et al., 1981; Fiedler, 2002; Amador et al., 2006). Así como el viento local genera corrientes marinas importantes en esta zona, también genera afloramientos, los cuales modifican la estructura vertical de las aguas (Fiedler, 2002; Kessler, 2006). Por otro lado, los procesos atmosféricos, como la alta radiación solar y precipitación que se dan en
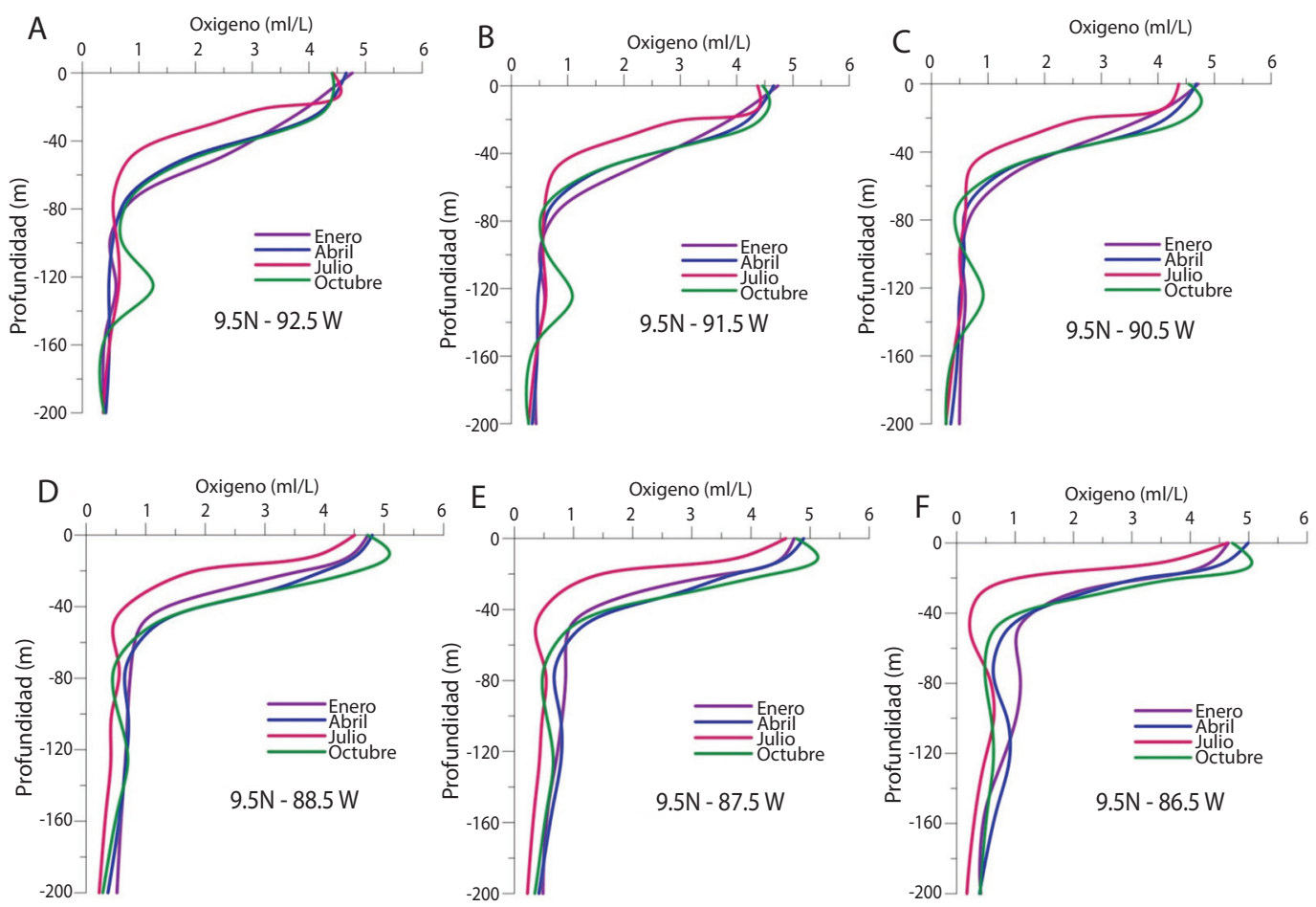

Figs. 11. Perfiles someros del oxígeno disuelto $(\mathrm{ml} / \mathrm{L})$ en el transepto oeste-este de Figura 1. 

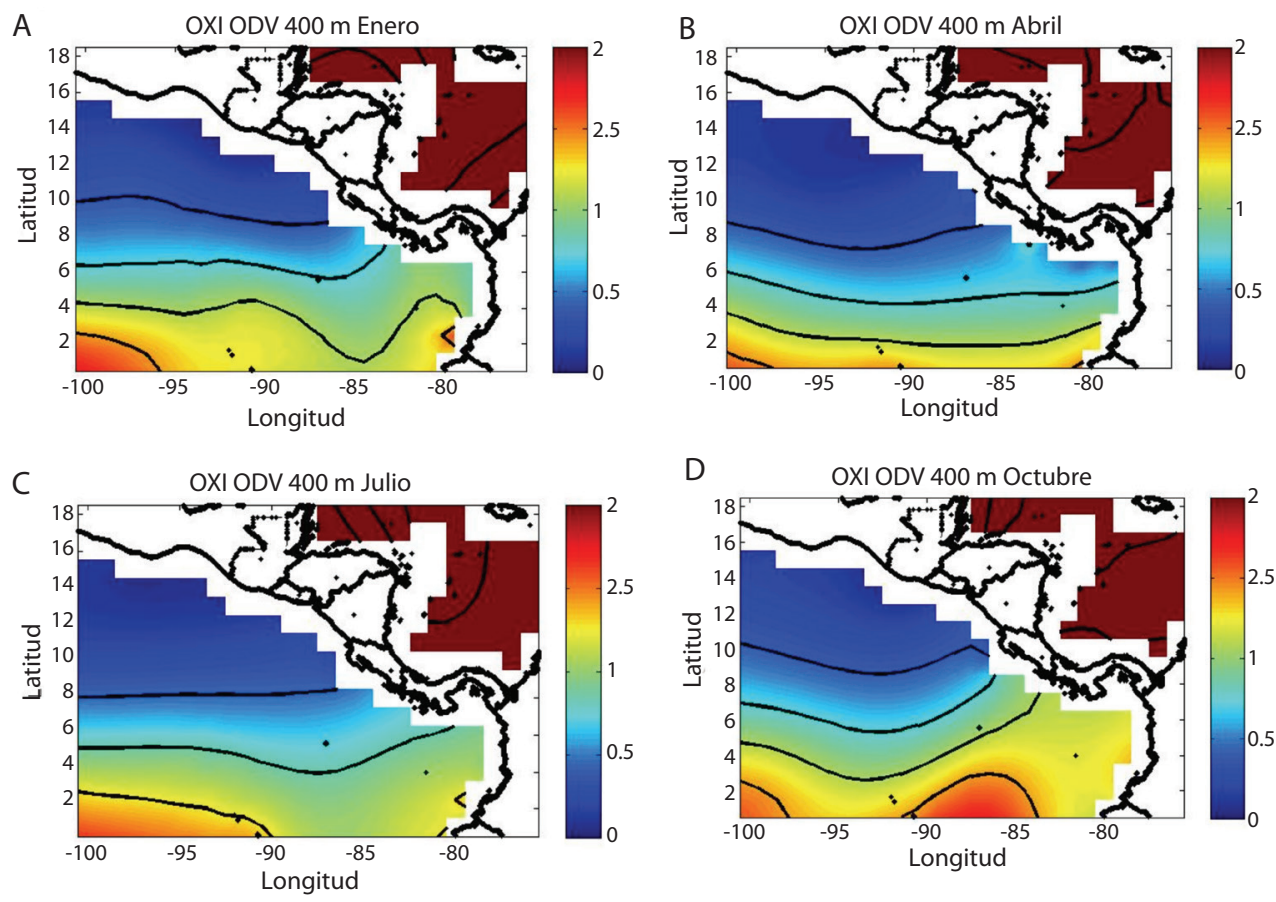

Figs. 12. Distribución espacial del oxígeno disuelto (ml/L) en la superficie del mar.

estas latitudes (Kanuss, 1978; Amador et al., 2006), también generan gradientes fuertes en la distribución espacial, como a través de la columna de agua. Otros procesos son principalmente mecanismos bioquímicos (Paulmier, Ruiz-Pino, Garçon, \& Farías, 2006). Aunque la distribución del oxígeno, fosfato, nitrato y silicato, también están relacionados con la estratificación termo-halina en la superficie (Fidler, \& Talley, 2006), el fosfato, nitrato y silicato, están más correlacionados con la estructura vertical del oxígeno disuelto (Bennett, 1963; Paulmier et al., 2006). En la medida que el oxígeno disminuye por respiración y oxidación de la materia orgánica, aumenta la concentración de estos otros elementos como producto de la reducción bacteriana (Broenkow, 1965). Aunque varios artículos escritos sobre el PTE tienen indicaciones de las distribuciones horizontales de estos elementos, la mayoría utilizan promedios trimestrales o desviaciones trimestrales respecto del promedio (e.g. Fiedler, \& Talley, 2006; Shang-Ping et al., 2005; Sasai, Richards, Ishida, \& Sasaki, 2012), o profundidades de la termoclina (Fiedler, 2002), y no promedios mensuales superficiales, como se hace en este artículo. El único artículo encontrado que muestra perfiles hasta $1000 \mathrm{~m}$ de estos elementos, es el trabajo Bronnkow (1965). Los gradientes y valores medidos en esa ocasión en $8.5^{\circ} \mathrm{N}$ y $88^{\circ} \mathrm{W}$, son comparables con los perfiles representativos del DTCR $\left(9.5^{\circ} \mathrm{N}-89.5^{\circ}\right.$ W) (Fig. 2B). Aunque es difícil ver variaciones entre algunos perfiles de las estaciones de la Fig. 2, por ejemplo: temperatura y salinidad, es claro que justo alrededor del centro del DTCR, se distingue un perfil de oxígeno disuelto con mayores gradientes hacia arriba y hacia bajo de la ZMO, que está alrededor de los 500m. Es decir, hay mayores concentraciones de oxígeno disuelto de estas aguas en comparación al resto de los perfiles en los extremos de los transectos (Fig. 1), al norte, este y oeste del DTCR.

Al principio del año (enero a abril) los vientos intensos sobre el Golfo de Papagayo y el Golfo de Panamá, mantienen afloramientos en estas regiones (Fielder, 2002). El afloramiento de Papagayo es aún sensible a latitudes 
como los $6^{\circ} \mathrm{N}$ y $95^{\circ} \mathrm{W}$ (Fig. 3A). Estos afloramientos condicionan la distribución superficial de temperatura, la salinidad y de oxígeno disuelto. La surgencia de aguas desde capas sub-superficiales, implica aguas más frías, más salinas, y con menor concentración de oxígeno disuelto (Fiedler, 2006; Kessler, 2006), que como lo menciona Wyrtki (1964), vienen de capas debajo de la termoclina $(75-200 \mathrm{~m})$, donde las temperaturas rondan los $12-14^{\circ} \mathrm{C}$.

El análisis de los datos de ODV en este trabajo, muestra que la variación climática mensual de los perfiles de temperatura, salinidad y oxígeno disuelto en la columna de agua, se dan sobre los $200 \mathrm{~m}$ de profundidad (Figs. $4,5,7,8,10,11)$, y sus variaciones son principalmente, una consecuencia de los procesos atmosféricos y oceánicos que se mencionaron anteriormente. La marcha mensual de los gradientes con profundidad de estos perfiles, dependen de la variación espacial e intensidad de los afloramientos generados en esta zona. Las estaciones en el límite norte muestran la mayor variabilidad climatológica de los perfiles de temperatura, salinidad y oxígeno, lo cual es coherente con la mayor variabilidad de los afloramientos que se dan al norte de los $9.5^{\circ}$ N. Sobre estas estaciones se puede encontrar una capa de mezcla de temperatura (Figs. 4A, B), salinidad (Figs. 7A, B), y hasta de oxígeno disuelto (Figs. 10A, B), en los primeros meses del año (enero a abril), lo cual está relacionado con la intensidad de los vientos que se generan durante estos meses (Amador et al., 2006; Alfaro, \& Cortés, 2012; Alfaro et al., 2012). En los meses de abril, julio y octubre en estas estaciones también se pueden encontrar inversiones en el gradiente de salinidad con profundidad (Figs. 7A, B, 8D, E, F) y del oxígeno disuelto (Figs. 10A, B), lo cual puede estar relacionado con la evaporación de las aguas superficiales (Knauss, 1978).

La distribución de la salinidad en la capa superficial de todas las estaciones (Fig. 6), es menor que la salinidad sobre la capa profunda (Figs. 7, 8), lo cual está relacionado a las altas precipitaciones que se dan sobre esta parte del PTE (Amador et al., 2006). Esta es la zona de menor salinidad de todos los océanos tropicales del mundo (Lizano, 2008).

Un resultado importante, fue la distribución espacial de salinidad para el mes de abril, dado que el mínimo está separado de la costa de Colombia, y ligado más bien al sur de Costa Rica. Este resultado lo muestra también el artículo de Fiedler \& Talley (2006), pero no fue resaltado. Como se sabe, el mes de abril es el mes en que comienza a llover en el Pacífico Sur de Costa Rica y en la Isla del Coco (Alfaro, 2008; Morales-Ramírez, Lizano, Acuña, Alfaro, \& Gómez, 2015). Revisando la distribución espacial de la precipitación en esta región de los Reanálisis de NCEP alrededor de abril (Fig. 13), se puede justificar este mínimo. La marcha

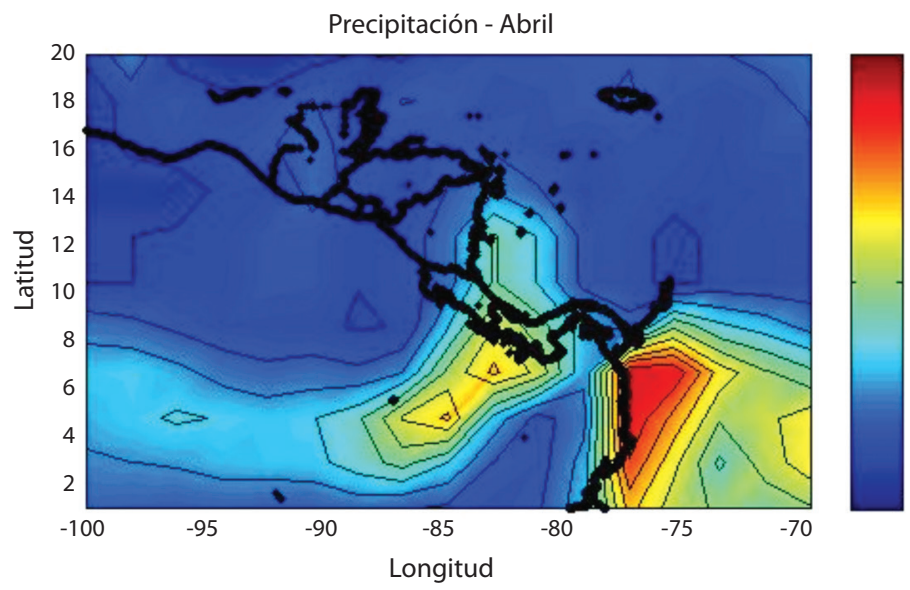

Fig. 13. Fig. 6. Distribución espacial de la precipitación $(\mathrm{Kg} / \mathrm{m} 2 / \mathrm{seg})$ en el mes de abril. 
hacia el norte de la ZCIT, genera alrededor de este mes ese máximo relativo de precipitación en esta zona (Magaña, Amador, \& Medina, 1999; Shang-Ping et al., 2005; Amador et al., 2006; Quirós, 2015; Hidalgo et al., 2015).

La distribución espacial superficial del oxígeno disuelto en el PTE está en relación con la variación espacial de los afloramientos del DTCR y del Golfo de Panamá, que tienen relación también, con en la marcha anual de la ZCIT. La menor concentración de oxígeno disuelto se da en el mes de enero y julio, justo cuando el viento genera afloramientos (Fiedler, 2002; Alfaro et al., 2012). La mayor concentración de oxígeno frente a las costas de Costa Rica, se dan alrededor de octubre, cuando no hay vientos alisios, y por lo tanto, no hay afloramiento y no hay consumo de oxígeno. Alrededor de octubre, también se comienza a notar una disminución de la concentración de oxígeno en superficie al frente y sur del Golfo de Tehuantepec, como una evidencia de los vientos fuertes, que ya para esta época, comienzan a soplar en esta región (Amador et al., 2006; Alfaro et al., 2012).

Los perfiles de oxígeno disuelto en los transectos estudiados en la columna de agua, también muestran básicamente, la dinámica del afloramiento en el DTCR. Tanto en los perfiles latitudinales, como en los longitudinales, la oxiclina es menos profunda alrededor de julio, posiblemente relacionados a la intensificación de los vientos alisios sobre esta zona, en el llamado "veranillo de San Juan" (Amador et al., 2006; Amador, 2008; Alfaro, 2014). La oxiclina más profunda se produce en octubre para la mayoría de los perfiles, de nuevo, asociados a los débiles afloramientos alrededor de este mes. Algunos de los perfiles al norte y oeste de DTCR, muestran un curioso lóbulo o máximo relativo de oxígeno a aproximadamente $130 \mathrm{~m}$ de profundidad en octubre, cuya fuente podría estar relacionada con corrientes sub-superficiales desde el oeste (Fiedler, \& Talley, 2006; Kessler, 2006; Karstensen et al., 2008).

Es claro que la existencia de la ZMO en el PTE está relacionada tanto al consumo de oxígeno disuelto, como a la pobre ventilación oceánica en esta región (Karstensen et al., 2008). La mayor advección de oxígeno disuelto a profundidades de $400 \mathrm{~m}$ (Fig. 12) (profundidad aproximada alrededor de la $\mathrm{ZMO}$ ), viene de aguas más profundas. Corrientes sub-superficiales y profundas son las que advectan oxígeno desde el sur del ecuador geográficos (Kessler, 2006; Chavez, \& Messié, 2009; Rincón-Martínez, Steph, Lamy, Mix, \& Tiedemann, 2011), evidente por ejemplo, a profundidades de los $200 \mathrm{~m}$ en los perfiles más al sur del transecto latitudinal (Figs. 10D, E, F), y también alrededor del mes de enero, donde hay mayor aporte (Fig. 12A). Estas mismas corrientes sub-superficiales (Paulmier, RuizPino, \& Garçon, 2011), son las que explican el aumento de oxígeno disuelto a profundidades mayores de $800 \mathrm{~m}$ (Fig. 2). Por otro lado, se argumenta también, que el mínimo de oxígeno está relacionado el calentamiento de las aguas superficiales (Fee, 2012), lo cual reduce la solubilidad de oxígeno e incrementa el gradiente de la termoclina. Esto último limita la convección y el intercambio de aguas más ricas en oxígeno desde la superficie, contribuyendo esto, con mayor expansión de la ZMO (Fiedler, $\&$ Talley, 2006). Con el calentamiento global, será más difícil el intercambio de aguas, que como lo señalan Karstensen et al. (2008) y Paulmier, Kriest \& Oschlies (2009), generará mayor perturbación en los ecosistemas marinos, y a la vez, una retroalimentación en la modificación del clima global.

\section{AGRADECIMIENTOS}

A los estudiantes Diego Garro, Lizdenia Arce y Paula Pérez por la colaboración en el manejo y graficación de datos. A la Vicerrectoría de Investigación de la UCR por el apoyo al proyecto 808-B0-040 adscrito al Programa 808-A9-902.

\section{RESUMEN}

El Domo Térmico de Costa Rica (CTCR) es un fenómeno oceanográfico en el Pacífico Tropical del Este (PTE). Esta es una zona biológicamente altamente productiva, 
con altas concentraciones de plancton, aves marinas, y grandes pelágicos, como atunes, delfines y ballenas. Pocos trabajos se han realizado sobre la variación estacional de la columna de agua en el CTCR. Aquí se analizó la distribución horizontal y vertical de algunos parámetros oceánicos para mostrar la dinámica del PTE, su influencia sobre del DTCR, las variaciones climáticas mensuales y las relaciones que justifican sus distribuciones. Datos climatológicos mensuales del Ocean Data View (ODV) desde 1900 hasta el 2009, fueron utilizados para elaborar perfiles en la columna de agua como temperatura, salinidad y oxígeno disuelto, y de sus distribuciones espaciales alrededor del Domo Térmico de Costa Rica (DTCR). Las variaciones mensuales de estos parámetros dependen de la intensidad y alcance de los fenómenos océano-meteorológicas en el Pacífico Tropical Este (PTE), las cuales están relacionadas con la migración norte-sur de la Zona de Confluencia Intertropical (ZCIT). La variación climática mensual de estas variables se desarrolla sobre los $200 \mathrm{~m}$ de profundidad desde la superficie. Se encuentra mayor variabilidad climática en los perfiles en la columna de agua en las estaciones al norte y al este del DTCR. Tanto las estaciones al norte del DTCR, como las más cerca de la costa, son las que tienen mayor influencia de los vientos al frente del Golfo de Papagayo y donde se produce mayor variación mensual en los afloramientos en esta región. La distribución y concentración del oxígeno disuelto depende de esta dinámica oceánico-atmosférica. El oxígeno es consumido por los procesos de respiración y oxidación de la materia orgánica que se dan alrededor del DTCR. Pero además, esta es una de las regiones de los océanos tropicales donde se encuentra una Zona de Mínimo Oxígeno (ZMO), que está relaciona también, con una pobre dinámica de las aguas o una falta ventilación oceánica. Las fuentes de oxígeno disuelto son ligadas con corrientes sub-superficiales que viene desde el oeste y desde el sur del ecuador geográfico.

Palabras clave: Ocean Data View, climatología, Pacífico Tropical Este, Domo Térmico de Costa Rica, oxígeno disuelto.

\section{REFERENCIAS}

Alfaro, E. J. (2008). Ciclo diario y anual de variables troposféricas y oceánicas en la Isla del Coco, Costa Rica. Revista Biología Tropical, 56(Suplemento 2), $19-29$.

Alfaro, E., \& Cortés, J. (2012). Atmospheric forcing of cool subsurface water events in Bahía Culebra, Gulf of Papagayo, Costa Rica. Revista de Biología Tropical, 60(Suplemento 2), 173-186.

Alfaro, E. J., Cortés, J., Alvarado, J. J., Jiménez, C., León, A., Sánches-Noguera, C., Nivia-Ruiz, J., \& Ruiz, E. (2012). Clima y temperatura superficial del mar en Bahía Culebra, Golfo de Papagayo, Costa
Rica. Revista Biología Tropical, 60(Suplemento 2), 159-171.

Alfaro, E. (2014). Caracterización del "veranillo" en dos cuencas de la vertiente del Pacífico de Costa Rica, América Central. Revista de Biología Tropical, 62(Suplemento 4), 1-15.

Amador, J. A. (2008). The Intra-Americas Sea Low-level Jet Overview and future research. Trends and Directions in Climate Research. Annals of the New York Academy of Sciences, 1146, 153-188.

Amador, J.A., Alfaro, E.J., Lizano, O.G., \& Magaña, V. (2006). Atmospheric forcing in the Eastern Tropical Pacific. Progress in Oceanography, 69, 101-142.

Bennett, E.B. (1963). An oceanographic atlas of the eastern tropical Pacific Ocean based on data from EASTROPIC Expedition, October-December 1955. Inter-American Tropical Tuna Commission Bulletin, 8, 33-165.

Brenes, C.L, Lavín, M.F., \& Mascarenhas Jr., A.S., (2008). Geostrophic circulation between the Costa Rica Dome and Central America. Deep Sea Research I, $55,608-629$.

Broenkow, W. (1965). The distribution of nutrients in the Costa Rica Dome in the eastern tropical Pacific Ocean. Limnology and Oceanography, 10(1), 40-52.

Chavez, F.P. \& Messié. M. (2009). A comparison of eastern boundary upwelling ecosystems. Progress in Oceanography, 83, 80-96.

Cromwell, T. (1958). Thermocline topography horizontal currents and "ridging" in the eastern tropical Pacific. Inter-American Tropical Tuna Commission Bulletin, 4, 135-164.

Fee, E. A. (2012). Extent of the oxygen minimum zone in the Eastern Tropical North Pacific. (Senior Thesis). University of Washington School of Oceanography. Seattle, Washington.

Fernández-Álamo, M., \& Färber-Lorda, J. (2006). Zooplankton and the oceanography of the eastern tropical Pacific: A review. Progress in Oceanography, 69, 318-359.

Fiedler, P. C. (1992). Seasonal climatologies and variability of eastern tropical Pacific surface waters. (NOAA Technical Report, NMFS, 109). Maryland, EEUU: NOAA/National Marine Fisheries Service.

Fiedler, P. C. (1994). Seasonal and interannual variability of coastal zone color scanner phytoplankton pigments and winds in the eastern tropical Pacific. Journal of Geophysical Research, 99, 18371-18384.

Fiedler, P. C. (2002). The annual cycle and biological effects of the Costa Rica Dome. Deep-Sea Research I, 49, 321-338.

Fiedler, P. C., \& Talley, L. D. (2006). Hydrography of the Eastern Tropical Pacific: A review. Progress in Oceanography, 69, 143-180. 
Hidalgo, H. G., Durán-Quesada, A. M., Amador J. A., \& Alfaro, E. J. (2015). The Caribbean Low-Level Jet, the Inter-Tropical Convergence Zona and the precipitation patterns in the Intra-Americas Sea: A proposed dynamical mechanism. Geografiska Annaler, Series A: Physical Geography, 97, 41-59. doi: 10.1111/ geoa. 12085

Hofmann, E. E., Busalacchi, A. J., \& O’Brien, J. J. (1981). Wind generation of the Costa Rica Dome. Science, 214, 552-554.

Kashino, Y., Ishida, A., \& Hosada, S. (2011). Observed ocean variability in the Mindanao Dome Region. Journal of Physical Oceanography, 41, 287-302.

Karstensen, J., Stramma, L., \& Visbeck, M. (2008). Oxygen minimum zones in the eastern tropical Atlantic and Pacific oceans. Progress in Oceanography, 77, 331-350.

Kessler, W. S. (2006). The circulation of the eastern tropical Pacific: A review. Progress in Oceanography, 69, 181-217

Knauss, J. A. (1978). Introduction to Physical Oceanography. Nueva York: Prentice-Hall.

Levitus, S., Antonov, J. I., Baranova, O. K., Boyer, T. P., Coleman, C. L., Garcia, H. E., Grodsky, A. I., Johnson, D. R., Locarnini, R. A., Mishonov, A. V., Reagan, J. R., Sazama, C. L., Seidov, D., Smolyar, I., Yarosh, E. S., \& Zweng, M. M. (2013). The World Ocean Database. Data Science Journal, 3, 229-234.

Lizano, O. G. (2008). Dinámica de las aguas alrededor de la Isla del Coco, Costa Rica. Revista de Biología Tropical, 56(Suplemento 2), 31-48.

Magaña, V., Amador, J. A., \& Medina, S. (1999). The Midsummer Drought over Mexico and Central America. Journal of Climate, 12, 1577-1588.

Morales-Ramírez, A., Lizano, O., Acuña, J., Alfaro, E., \& Gómez, E. (2015). Rasgos oceanográficos en el Golfo Dulce, Pacífico de Costa Rica: una revisión para la toma de decisiones en conservación marina. Revista de Biología Tropical, 63(Suplemento 1), 131-160.

Muñoz, A. C., Fernández, W., Gutiérrez, J. A., \& Zárate, E. (2002). Variación estacional del viento en Costa Rica y su relación con los regímenes de lluvia. Tópicos Meteorológico y Oceanográficos, 9(1), 1-13.

Palacios, D. M., Bograd, S. J., Foley, D. G., \& Schwing, F. B. (2006). Oceanographic characteristics of biological hot spots in the North Pacific: A remote sensing perspective. Deep Sea Research Part II: Topical Studies in Oceanography, 53, 250-269.

Paulmier, A., Ruiz-Pino, D., Garçon, V., \& Farías, L. (2006). Maintaining of the Eastern South Pacific Oxygen Minimum Zone (OMZ) off Chile. Geophysical Research Letters, 33, L20601.
Paulmier, A., Kriest, I., \& Oschlies, A. (2009). Stoichiometries of remineralisation and denitrification in global biogeochemical ocean models. Biogeosciences, 6, 923-935.

Paulmier, A., Ruiz-Pino, D., \& Garçon, V. (2011). CO2 maximun in the Oxygen Minimun Zone (OMZ). Biogeosciences, 8, 239-252.

Pennington, J. T., Mahoney, K. L., Kuwahara, V. S., Kolber, D. D., Calienes, R., \& Chavez, F. P. (2006). Primary production in the eastern tropical Pacific: a review. Progress in Oceanography, 69, 285-317.

Quirós, E. (2015). Variabilidad climática de la Zona de Convergencia Intertropical y su influencia en la hidrometeorología centroamericana. (Tesis de Maestría). Universidad de Costa Rica, San José, Costa Rica.

Rincón-Martínez, D., Steph, S., Lamy, F., Mix, A., \& Tiedemann, R. (2011). Tracking the equatorial front in the eastern equatorial Pacific Ocean by the isotopic and faunal composition of planktonic foraminifera. Marine Micropaleontology, 79, 24-40.

Sasai, Y., Richards, K. J., Ishida, A., \& Sasaki, H. (2012). Spatial and temporal variabilities of the chlorophyll distribution in the northeastern tropical Pacific: The impact of physical processes on seasonal and interannual time scales. Journal of Marine Systems, 96, 24-31.

Shang-Ping, X., Xu, H., Kessler, W. S., \& Nonaka, M. (2005). Air-Sea Interaction over the Eastern Pacific Warm Pool: Gap winds, thermocline dome, and atmospheric convection. Journal of Climate, 18, $5-20$.

Umatani, S., \& Yamagata, T. (1991). Response of the Eastern Tropical Pacific to meridional migration of the ITCZ: the generation of the Costa Rica Dome. Journal of Physical Oceanography, 21, 346-363.

Willett, C. S., Leben, R., \& Lavín, M. F. (2006). Eddies and mesoscale processes in the eastern tropical Pacific: A review. Progress in Oceanography, 69, 218-238.

Wyrtki, K. (1964). Upwelling in the Costa Rica Dome. Fishery Bulletin, 63, 355-372.

Wyrtki, K. (1966). Oceanography of the eastern equatorial Pacific Ocean. Oceanography and Marine Biology Annual Review, 4, 33-68.

Wyrtki, K. (1967). Circulation and water masses in the eastern equatorial Pacific Ocean. International Journal of Oceanology and Limnology, 1, 117-147.

Zárate, E. (1978). Comportamiento del viento en Costa Rica. Nota de Investigación No. 2. San José, Costa Rica: Instituto Meteorológico Nacional. 